\title{
DOCUMENTOS INÉDITOS PARA LA HISTORIA DE MAGALLANES "MEMORÁNDUM REFERIDO A LOS PATAGONES"
}

\author{
Introducción y notas \\ por Mateo Martinic B.
}

\section{INTRODUCCIÓN}

La preocupación y gentileza de Mrs. Jean Cameron, encargada del Archivo de las Islas Falkland, ha puesto recientemente a nuestra disposición un documento manuscrito titulado Memorando respecting the Patagonians, que fue encontrado en una revisión de papeles de dicho repositorio y que se halla catalogado como "Falkland Islands Archives Incoming Miscellaneus Letters Vol. H2 ff. 51-54". Se trata de un documento breve, de sólo cinco páginas, sin firma y sin fecha, escrito en lengua inglesa, posiblemente por un oficial naval perteneciente a un barco de Su Majestad Británica de paso por el estrecho de Magallanes, con el fin de informar acerca de los naturales de la costa patagónica. Sin embargo hay algunos antecedentes que permiten fijar la época de su redacción hacia 1840-41.

En efecto, en el documento se hace mención a tres personajes de la historia local como son "San León", "Isaac" y el jefe aónikenk "Wissale". Estos, respectivamente, no eran otros que el oriental (uruguayo) Santos Centurión, criollo aindiado establecido entre los indígenas patagones allá por los años de 1820 , en medio de los que adquirió algún predicamento tanto por haberse unido con una mujer indígena y adoptado sus costumbres, como por el hecho de su condición de "civilizado" que permitía una más fácil relación con los foráneos, fuesen estos navegantes de diferente nacionalidad o autoridades y funcionarios chilenos, en este caso luego de la ocupación formal del territorio sudpatagónico y fueguino en 1843 , por disposición del Gobierno de Chile. No obstante su apellido en la forma consignada, el mismo aparece mencionado también en relaciones de terceros como Santorín, Santo Río y, curiosamente, Santo León y San León, como en el documento al que se hace referencia.

Isaac Williams, era un negro norteamericano que hacia 1840 había desertado del buque de su bandera en que viajaba como marinero, a su paso por el Estrecho, y fue acogido por los indígenas patagones, cuyo idioma aprendió, lo que le permitió servir como lenguaraz en las relaciones de los mismos con los blancos, máxime si eran de habla inglesa. Wissale o Wissel, para los británicos y norteamericanos, y Huisel para los chilenos, fue un jefe con el que trataron durante algunos años las autoridades de Fuerte Bulnes. Es decir, se hace referencia a personajes de vigencia comprobada durante los años de 1830 y hasta pasado 1850. Ellos, principalmente Centurión, y está visto igualmente Isaac Williams, fueron de diferente modo los informantes para los foráneos respecto del mundo indígena aónikenk. De allí que lo sustancial del documento son las noticias que el desconocido interlocutor obtuvo de sus informantes sobre la materia para, a su tiempo, transmitirlas a la autoridad colonial británica.

Se recoge en el manuscrito la noción general, bien que vaga, que los aónikenk meridionales (y los que convivían con ellos) poseían sobre el ámbito indígena patagónico desde el estrecho de Magallanes hasta el norte del río Negro, incluyendo el número y denominaciones (algunas ciertamente novedosas y curiosas) de los diferentes grupos étnicos, su ubicación geográfica relativa y la cantidad 
de individuos que las componían. Son éstos, datos que deben ser valorizados de manera diferente, en especial en lo tocante al último aspecto que, evidentemente sólo podía ser estimativo, pecándose más por exceso como por defecto en la cuantificación. En la etnonimia, la identificación que se da exige aceptar la mutación que hubo de originarse en el nombre individualizador según pudo ser pronunciado en lengua indígena (tampoco la original) y lo oído o retenido y escrito por el interlocutor extranjero, como pudo ser el presunto oficial inglés.

Se entrega también información sobre los vecinos meridionales de los áonikenk que, de primera parece estar referida a los sélknam, pues se los sitúa en la costa norte de la Tierra del Fuego. Pero, bien leída, la mención es para los canoeros kawéskar, a los que para la época se consideraba genéricamente "fueguinos", $y$, en particular, para aquellos de la parcialidad costera de la península de Brunswick con los que los aónikenk tenían un antiguo trato, en una relación de dominador/dominado y que generaría históricamente un mestizaje cultural del que nos hemos ocupado reiteradamente. En el caso se agregan antecedentes sobre las circunstancias voluntarias o forzadas que los transformaban de canoeros en gente de a pie, en tierra firme.

Se brindan asimismo noticias sobre las creencias y prácticas religiosas de los aónikenk, a los que se nombra "Patagones", con mención especial para los chamanes y sus prácticas, así como al ritual funerario y al luto por los difuntos.

La siguiente referencia etnográfica corresponde a los que se llaman "Tatchwell", que deberían ser tenidos como los "manzaneros" históricos (huilliches mapuchizados que habitaban el País de las Manzanas), por la ubicación geográfica que se les da, como lo es el distrito septentrional del lago Nahuelhuapi. Más al norte de los mismos son situados los "Shet-tich" o "Tchucats", aunque de manera confusa -está visto que los informantes distaban de ser expertos en geografía patagónica-, pues de primera parece una referencia genérica para los "pampas", pero después se los identifica con los pehuenches. En cualquier

Véase entre nuestro trabajo "Convivencia KawéskarAónikenk en el itsmo de Brunswick, Patagonia austral, Chile. Un caso de mestizaje cultural". En Levantando piedras, desenterrando huesos... y develando arcanos. Actas VI Jornadas de Arqueología de la Patagonia, págs. 927-940, Punta Arenas, 2007. caso, la confusión es explicable pues unos y otros estaban ubicados al norte de los manzaneros.

Luego de esta mención, que, como todo el texto se apostilla por separado junto con la transcripción del manuscrito, el mismo concluye abruptamente dejando la duda acerca de si efectivamente así fue, o si continuaba una parte final. El espacio en blanco que se observa en la quinta y última página parece afirmar la primera posibilidad.

La transcripción y comentarios que se hacen de este memorando hasta ahora inédito sobre los patagones, no tiene más objeto que el de ponerlo a disposición de los estudiosos de la etnografía patagónica, a quienes corresponderá con propiedad cabal conocer e interpretar las informaciones que contiene el documento, correlacionarlas con las noticias ya entregadas en otras fuentes ${ }^{* *} y$, en definitiva, valorizarlas para así, ojalá, poder llegar a comprender mejor el arcano étnico y cultural de los pueblos patagónicos.

\section{MEMORANDUM REFERIDO A LOS PATAGONES}

Hay cinco tribus de Patagones, una al norte del Río Negro, tres al sur de este río y una en la costa oeste de la Cordillera.

Estas tribus son respectivamente las siguientes

Lulla-much---Shuan mannuil - Norte del Río Negro -- 4.000 a 5.000

** Cfr. especialmente el valioso libro Misionando por la Patagonia Austral 1858-1865 de Teófilo Schmid, con prólogo y comentarios del Dr. Milcíades A. Vignati, publicado por la Academia Nacional de la Historia (Buenos Aires, 1964), y, entre otros varios, los artículos "Informaciones extraídas del diario inédito de Santiago Dunne, secretario de la Gobernación de Magallanes (1845)", de nuestra autoría (Anales del Instituto de la Patagonia, Serie Ciencias Humanas, vol. 28, Punta Arenas 2000) y "Documentos inéditos para la historia de Magallanes", con presentación y notas nuestras (Anales del Instituto de la Patagonia, Serie Ciencias Humanas, vol. 29, Punta Arenas 2001) y los trabajos de carácter etnográfico del Dr. Rodolfo Casamiquela, en particular el artículo "Reflexiones acerca de la significación de los tehuelches septentrionales australes occidentales (Chüwach a Künna)" (En Poblamiento del noroeste del Chubut. Aportes para su historia, por Débora Finkelstein y María Marta Novella, compiladoras, Fundación Amegnino, Esquel 2005).

$*$ Traducción hecha por el autor. 
Payni-Ken ---- Gu-Kamu1 ---- Sur del Río Negro --- 1.500

Karmas ---- Tawelchi ${ }^{2}$---- Puerto Deseado --- 1.200 Río Santa Cruz

Harwan-eki ${ }^{3}$--- Wissale ${ }^{4}$---- Río Gallegos

Estrecho de Magallanes 2.000

tatchwell ${ }^{5}$ Cho-karro ------- Oeste de la Cordillera $4.000^{6}$

\section{[ilegible]}

La última sílaba se pronuncia como "sale"

La población dada es un cálculo grueso en números redondos obtenido del [ilegible] testimonio de San León ${ }^{8}$, Isaac ${ }^{9}$ y los nativos, pero no es muy cuidadoso.

Todas las tribus hablan una sola lengua ${ }^{10}$ y se denominan a sí mismos, en general, bajo el

1 Las primeras dos palabras recuerdan el nombre "Paynakán" con el que también era conocido hacia fines del siglo XIX el jefe Francisco Blanco, que durante los años de 1890 y hasta mediados de la década de 1900 estuvo asentado con su grupo de manera recurrente en el valle medio del río Vizcachas, Ultima Esperanza. Asimismo al topónimo "Payne" recogido por vez primera por el explorador Juan T. Rogers durante su primera expedición al lago Argentino (1877). Las dos palabras finales recuerdan el gentilicio Gününaken de otros autores.

2 Claramente se corresponde con el difundido gentilicio "Tehuelche".

3 Transcripción gráfica corrupta, a nuestro entender, de la voz "aónikenk", gentilicio identificatorio de los cazadoresrecolectores de la parte meridional oriental de la Patagonia. Recuérdese que la fonía indígena era de tipo gutural.

4 Este nombre y sus variantes Wisel o Huisel, identificaban, según se ha visto, al jefe del importante grupo aónikenk que tenía sus paraderos en el distrito situado entre el estrecho de Magallanes, incluida la parte norte de la península de Brunswick, y el río Gallegos.

5 Voz derivada de "tatchwal" una de varias formas con que se identificaba a un ser maligno y que en cierto modo identificaba a los tehuelches septentrionales australes occidentales según Casamiquela.

6 Véase más adelante la nota 34.

7 El encomillado es nuestro para conservar la palabra inglesa.

8 Referencia a Santos Centurión (Santorín, Santo Río, Santurión, Santo León y San León), criollo que vivía entre los aónikenk, según se ha visto antes.

9 Referencia a Isaac Williams, negro norteamericano que habitaba entre los aónikenk.

10 Ponemos en duda esta aseveración que atribuimos más al autor del memorando que a sus informantes, quienes no podían ignorar el hecho de que cada grupo étnico tenía su propio idioma. Aunque, no obstante, podían entenderse entre sí. nombre de Choanik ${ }^{11}$ que puede ser visto como el apelativo distintivo de la nación Patagona.

Los nativos de la costa norte de la Tierra del Fuego se llaman a sí mismos y son llamados por los Patagones Ireys ${ }^{12}$. Antiguamente muchos de ellos fueron hechos cautivos al alcanzar la costa del continente, pero ahora no sólo tienen autorización para trabajar en libertad, sino que son bien tratados cuando ellos arriban, aunque los Patagones invariablemente destruyen sus canoas con las que ellos se transportan, para evitar su regreso y así incrementar el número de su propia tribu. Se ha sabido de casos en que los Ireys mismos rompen sus canoas al momento de llegar a la costa norte. Los Ireys son grandes ladrones abandonados a sí mismos, pero son mantenidos en cierto grado de orden cuando se asocian con los Choanik ${ }^{13}$.

\section{LOS PATAGONES}

No tienen ídolos o dioses establecidos, pero creen en un espíritu bueno y dos malos.

$$
\begin{aligned}
& \text { Nombre del buen espíritu ----- Kete-a-once } \\
& \text { a veces llamado ----------- Tchur }
\end{aligned}
$$

$$
\begin{aligned}
& \text { El mal espíritu es llamado ----- Ous-kin } \\
& \text { a veces ----- U-hom }
\end{aligned}
$$

El otro espíritu malo God-lin (la o suena como a en goadload)

Ellos se imaginan que el espíritu bueno reside en el sol y que los buenos espíritus en la luna.

$$
\text { El primero es llamado -------- Su-ani }
$$

11 Este gentilicio deriva por grafía de la pronunciación de la voz indígena "tsonk", que se pronuncia "Chonk", significativo de "gente". En esto, así como en el número de grupos étnicos patagónicos, hay coincidencia con la información recogida años después por el misionero Schmid.

12 Esta es la primera noticia que conocemos sobre este gentilicio. No consta, aparte de lo afirmado, que los aónikenk nombraran así a los canoeros, pero sí con la denominación "zapallos" o "supalios" y variantes, materia de la que nos ocupamos en uno de los trabajos mencionados.

13 Esta información se corresponde en general, con la obtenida en su momento por P. P. King y R. Fitz Roy entre los aónikenk de San Gregorio. 
El último ------------ Kaani-genkin ${ }^{14}$ (la g suena como en go) va sea a l sol o a la luna. Ellos no tienen ideas respecto de la transmigración de las almas, pero creen que ellos permanecen en el sol o en la luna después que las almas se separan del cuerpo.

Quansi ${ }^{15}$, quien murió hace unos dos años atrás ${ }^{16}$ era el jefe principal de las tres tribus Choanik al sur del Río Negro ${ }^{17}$ como lo es ahora Wissale, y durante su gobierno mató a todos los brujos y hechiceros ${ }^{18}$ exceptuando a dos que están ahora en la tribu de Oazy Harbour ${ }^{19}$. Estos individuos se ocupan a veces en [ilegible] calamidad o la llegada de la muerte para rogar a los espíritus en el sol,

14 Todas estas denominaciones, con la excepción que se indica más adelante, deben ser tomadas como una primicia, pues hasta ahora eran desconocidas. Las mismas no se corresponden con los nombres que los aónikenk daban a sus deidades o espíritus superiores, como era el caso de Kooch, para el principal de ellos (también Seecho, Wekkon o Ushua); otro tanto sucede con el espíritu maligno, el Gualicho. No se sabía tampoco de denominaciones para los espíritus que habitaban en el sol y en la luna. La excepción se refiere al primer nombre "Kete-a-once", ya que con anterioridad habíamos encontrado en la relación de Schmid la frase kete ama win?, que significa ¿cómo se llama esto? en aonikoaish (op. cit., pág. 34), en la que la palabra inicial es idéntica a la correspondiente del nombre de que se trata. Pero más allá de eso no encontramos explicación

15 Este nombre lo habíamos encontrado antes únicamente en la relación de autor anónimo de que trata nuestro trabajo citado (2001), bajo la variante Cuansel. Todo indica que ese individuo fue una autoridad que mereció el afecto de sus paisanos: "el jefe más digno, respetado i temido de los Indios", según ese incógnito informante, y con vigencia probable durante los años de 1820 y prácticamente todos los de 1830. Quizá fuera el mismo al que King y Fitz Roy llamaron Bysante.

16 Esta mención cronológica bastante precisa, relacionada con la fecha que da el desconocido informante de nuestro trabajo mencionado para el asesinato de Cuancel, esto es, 1839, nos permite situar hacia 1841-42 la fecha del informe que se publica y apostilla.

17 El autor del memorando insiste en subordinar a los grupos étnicos del sur del río Negro bajo una sola jefatura, lo que no nos parece que haya sido así alguna vez.

18 Es sabido que los chamanes podían pagar con su vida cuando fallaban en las curaciones de los enfermos y se les imputaba la responsabilidad de su fallecimiento.

19 Es esta una nueva afirmación que da cuenta de la existencia de una parcialidad occidental de los aónikenk en el distrito del Estrecho, conocida por su asentamiento frecuente en campos próximos a la bahía Oazy. cuando lo hacen se arrodillan con las manos hacia el supuesto objeto de su adoración ${ }^{20}$.

Los hombres que realizan estos oficios son llamados ---- Kukench

Las mujeres Bawk $^{21}$

Los muertos son enterrados generalmente el día después de su fallecimiento. Ellos son depositados derechos en la tumba para siempre, con sus cabezas puestas hacia el oeste. Los toldos, mobiliario y cualquier objeto perteneciente al difunto son quemados; todos los otros artículos, tales como lanzas, cuchillos... son enterrados con el cuerpo, el que es previamente envuelto con una capa nueva. Los deudos soplan entonces sobre la tumba, golpeándose sus cabezas con las manos. Los caballos pertenecientes al difunto son sacrificados y sus cueros cortados y transformados en cojines pintados para [ilegible] por sus parientes ${ }^{22}$.

Los símbolos de luto son diferentes. Los parientes masculinos se hieren las piernas y las mujeres jóvenes las mejillas, y las adultas se cortan el cabello ${ }^{23}$. Los hombres se untan los dedos en la sangre que ha manado de las heridas y aspergen hacia el sol golpeándose el pecho al mismo tiempo y ofreciendo una oración de rodillas al supuesto espíritu24.

Tres personas, un hombre, su esposa e hijo pertenecientes a la Tribu Tatchwell estaban en Oazy Harbour, y de uno de ellos obtuve la siguiente información.

20 Esta información reitera la noticia más explícita y detallada proporcionada por el informante de marras (Anales..., vol. 29, pág. 219), en que se describe la ceremonia de invocación o rogativa al sol, nunca antes mencionada, que se sepa.

21 Denominaciones ciertamente novedosas, pues hasta ahora a los chamanes se les conocía por el nombre específico de calamelouts (según Schmid) y variantes tales camalasque (Viedma) y carmelucho (de acuerdo con el informante anónimo de 2001), derivados de la voz kälamuláwetrr (Vignati, op. cit., pág. 209).

22 Esta información complementa en detalles la descripción del misionero Schmid (op. cit. Págs. 185 y 186), y ambas, a su vez, son congruentes con la del informante anónimo mencionado.

23 En cuanto a la observancia del luto, aquí se difiere tanto de lo recogido por Schmidt como por el informante anónimo, al incorporar la práctica de las heridas rituales (faciales) en las mujeres jóvenes.

24 Esta es una novedad interesante en tanto que se da cuenta de un ritual nunca antes conocido y que se relaciona con una posible adoración al sol. 
El distrito habitado por los Tatchwell es húmedo y sumamente boscoso con árboles de gran tamaño ${ }^{25}$. Sus toldos [ilegible] y estatura son similares a los de las otras tribus patagonas. Ellos tienen sin embargo canoas pero son empleadas solamente para cruzar ríos y seguramente se trata de una armazón liviana cubierta con cueros de guanaco ${ }^{26}$. Ellos no usan remos pero cruzan sujetándose de la cola de los caballos que nadan delante de ellos ${ }^{27}$.

Su país está ubicado aproximadamente al noroeste de Oazy Harbour, pero para alcanzarlo es necesario viajar mucho hacia el norte, ya que más al sur no hay pasos buenos para que los caballos crucen la cordillera aunque ellos no lo hacen con frecuencia ${ }^{28}$.

25 Es obvio que los informantes se refieren al sector precordillerano oriental, en particular al pedemontano donde abundan los árboles de grandes diámetros y alturas gracias a la alta precipitación pluvial anual.

26 Este dato es especialmente interesante pues confirman, en la primera parte de la información, el dominio de la navegación por los aborígenes de tierra adentro pertenecientes al ámbito cultural mapuche, lo que incluye las parcialidades étnicas del oriente de la cordillera de los Andes. Al respecto es aclaratorio el trabajo de Miguel Chapanoff "Algunos antecedentes etnohistóricos y etnográficos acerca de la navegación de origen prehispánico en la zona centro sur de Chile: El uso de canoas monóxilas" (Actas Jornada de Historia Naval y Marítima 2006, Valparaíso) con pruebas reiteradas acerca de la navegación en embarcaciones de esa especie en lagos y ríos andinos, incluyendo la oriental. En cuanto a la segunda parte de la información, esto es, que la canoa era "de armazón liviana y cubierta con cueros de guanacos", la misma nos merece dudas pues el tipo de embarcación a que se hace mención parece más propio de una zona desprovista naturalmente de árboles y, por tanto, de uso más habitual en sectores alejados de la región andina.

27 Relacionando esta última oración con la parte final de la precedente, creemos que estamos ante una posible confusión de los informantes, por el hecho de relacionar dos prácticas de efectiva ocurrencia en las costumbres aborígenes, pero propias de y circunstancias diferentes. Al respecto cabe recordar la descripción hecha por Benjamín F. Bourne en la obra en que da cuenta de su cautiverio entre los aónikenk en 1848, que incluye asimismo una ilustración que muestra el cruce del río Santa Cruz por los indios utilizando una especie de cestas remolcadas por caballos nadando.

28 Es cierto que tomando a la bahía Oazy como punto de referencia, las primeras posibilidades de cruce del macizo andino se dan muy al norte de la misma, recién hacia los $45^{\circ} \mathrm{S}$, esto es en la región de Aysén. Sin embargo, en el contexto histórico, los atraviesos cordilleranos están situados a partir del lago Nahuelhuapi hacia el norte.
En la vecindad de este cruce hay una gran lago con una isla en él ${ }^{29}$. Esta parte del país y los alrededores del lago son habitados por una Tribu llamada Shet-titch cuyos [ilegible] son denominados Tchucats $^{30}$. Ellos son más numerosos que todas las otras tres tribus Choanik en conjunto. Usan plumas de avestruz en sus cabezas, ponchos de lana y una especie de pantalones, cultivan la tierra y tienen manadas numerosas de ovejas y caballos. La lengua es diferente de aquella de las tribus Choanik. Ellos comercian ocasionalmente con los asentamientos hispanoamericanos. A través de esta gente cruzan la cordillera y entonces se dirigen hacia el SW31.

El lago mencionado más arriba es llamado Chobit ${ }^{32}$ por ellos, está a unos siete días a caballo desde Oazy Harbour pero a los Tatchwell (tomando en cuenta las sinuosidades de la ruta por el bosque) podría tomarles unos diez días más ${ }^{33}$.

Otra tribu llamada Eaks fue mencionada también por los mismos individuos. Ellos habitan un distrito al norte de los Tatchwell, entre la cordillera y el mar, pero hay poca comunicación

29 Es seguro que la referencia geográfica corresponde al lago Nahuelhuapi, por su tamaño y porque tiene una isla en su parte occidental.

30 Ninguno de los dos gentilicios nos era conocido y para los mismos no hallamos explicación acerca de su significado.

31 Los pasos más frecuentados desde tiempo inmemorial son los de Puyehue, Ranco y Villarrica o Tromen.

32 El topónimo nos recuerda la voz "Chubut" o "Chupat", pero no acertamos con la posible relación entre ellos.

33 Este doble cálculo de distancia según demora nos resulta especialmente confuso, pues no parece incluir las paradas obligadas en el trayecto. En todo caso los "siete días" nos parecen un tiempo insuficiente para cubrir la supuesta distancia y alcanzar el destino esperado. La segunda estimación de tiempo parece más razonable, pero tampoco es satisfactoria. En este punto, sólo como referencia y contando únicamente las jornadas de cabalgata, nos apoyamos en Raúl C. Rey Balmaceda, quien a su vez basado en el explorador Carlos M. Moyano, afirma que las caravanas indígenas avanzaban entre cinco y seis leguas por día, esto es, aproximadamente entre 25 y 30 kilómetros (Geografía Histórica de la Patagonia, Ediciones Cervantes, Buenos Aires, 1976, pág. 69). Sobre esta base pensamos que el cálculo de los informantes pecó por defecto, y que una distancia como la que hay entre la bahía Oazy y el supuesto paso transcordilleramo al norte del Nahuelhuapi, vale decir, unos 1.500 kilómetros, debió demorar entre cuatro y cinco meses de marcha. 
entre los dos pueblos ya que su lengua difiere ${ }^{34}$ $y$ en una dirección hay un gran río que ellos no pueden cruzar en sus canoas. Los Eaks son más bajos que los Patagones y usan ponchos ${ }^{35}$.

Parece probable que el lago llamado Chobit por estas gentes sea el mismo que en el testimonio

34 Entendemos que esta mención como una referencia a alguno de los grupos étnicos que se ubicaban al este del río Limay y al norte del Negro, genéricamente "indios pampas".

35 Esta afirmación confirma nuestra opinión de la nota precedente. de Viedma es marcado como Chapar en el mapa ${ }^{36}$, y el uso de plumas de avestruz en el cabello y otras particularidades referidas por el hombre Tatchwell (Wao) aunque principalmente la primera basta para identificar a los Shet-titch con los Pewenches de cuya nación son probablemente una tribu.

36 Es un error de los informantes o del redactor del memorando. Francisco de Viedma descubrió en 1782 el lago andino que los indígenas llamaban Cápar, actual Viedma, depósito situado muy lejos hacia el sur del denominado Chobit, equivocación que no debe sorprender dado el gran desconocimiento que había acerca del interior de la Patagonia a mediados del siglo XIX. 